Original

\title{
Susceptibility of Heterozygous p53 Deficient CBA Mice to Induction of Liver Proliferative Lesions by Phenobarbital after Dimethylnitrosamine Initiation
}

\author{
Hiroshi Onodera ${ }^{1}$, Kunitoshi Mitsumori ${ }^{1,2}$, Hisayoshi Takagi ${ }^{1}$, Kazuo Yasuhara ${ }^{1}$, \\ Takatoshi Koujitani ${ }^{1}$, Touru Tamura ${ }^{1}$, Toshio Imai ${ }^{1}$, and Masao Hirose ${ }^{1}$ \\ ${ }^{1}$ Division of Pathology, National Institute of Health Sciences, 1-18-1 Kamiyoga, Setagaya-Ku, Tokyo 158-8501, Japan \\ ${ }^{2}$ Laboratory of Veterinary Pathology, Tokyo University of Agriculture and Technology, 3-5-8, Saiwai-cho, Fuchu, \\ Tokyo 183-8509, Japan
}

\begin{abstract}
To investigate the susceptibility of heterozygous p53-deficient CBA mice [p53 (+/-) mice] to promotion of liver proliferative lesions in a two stage hepatocarcinogenesis model, $30 \mathrm{p} 53(+/-)$ mice and 30 wild-type littermates [p53 $(+/+)$ mice] received an i.p injection of $5 \mathrm{mg} / \mathrm{kg}$ of $\mathrm{N}$-nitrosodimethylamine (DMN), and from one week later, each group was given free access to drinking water containing 0.05 or $0 \%$ of phenobarbital (PB) for 26 weeks. The final body weights were significantly decreased in both p $53(+/-)$ and p53 (+/+) mice of the DMN+PB compared to the DMN alone groups and the liver weights were significantly increased. The survival rate was 67 and $73 \%$ in p53 (+/-) and p53 (+/ + ) mice of the $\mathrm{DMN}+\mathrm{PB}$ group, respectively, and there were no deaths in any of the mice receiving DMN alone. The incidences of eosinophilic foci in the liver $(90$ and $54.6 \%$ in p53 (+/-) and p53 (+/+) mice, respectively) in the DMN $+\mathrm{PB}$ groups were significantly higher than those with DMN alone $(6.7 \%$ in $\mathrm{p} 53(+/-)$ mice, $0 \%$ in $\mathrm{p} 53(+/+)$ mice). The incidences of clear cell foci and hepatocellular adenomas were 10.0 and $9.1 \%$, and 60.0 and $27.3 \%$, respectively, in p53 $(+/-)$ and $\mathrm{p} 53(+/+)$ mice receiving DMN+PB. These lesions were not seen in the DMN alone group. The PCNA labeling indices for eosinophilic foci and hepatocellular adenomas in the DMN+PB group were significantly higher in p53 (+/-) than in p53 (+/+) mice. The present results suggest that p53 (+/-) CBA mice are very susceptible to promotion of the development of liver proliferative lesions by PB after DMN initiation. (J Toxicol Pathol 2001; 14: 273-278)
\end{abstract}

Key words: hepatocarcinogenesis, susceptibility, p53 knockout mice, N-nitrosodimethylamine, phenobarbital

\section{Introduction}

Recently, in worldwide trials to investigate the utility of two stage carcinogenesis models, newborn mice and genetically altered mice have been utilized for short-term testing alternatives to the current mouse carcinogenicity studies.

In particular, since loss and mutations of $\mathrm{p} 53$ gene have been associated with various human malignant tumors ${ }^{1}, \mathrm{p} 53$ knockout mice in which the p53 suppressor gene is inactivated have received much attention for detection of carcinogenicity with high sensitivity ${ }^{2}$. Spontaneous tumors such as thymic lymphomas or sarcomas are reported to develop at an early age in homozygous p53 knockout mice [p53 (-/-) mice] with bilateral p53 alleles inactivated ${ }^{3}$, so that

Received: 20 June 2001, Accepted: 22 August 2001

Mailing address: Hiroshi Onodera, Division of Pathology, National Institute of Health Sciences, 1-18-1 Kamiyoga, Setagaya-Ku, Tokyo 158-8501, Japan

TEL: 81-3-3700-9845 Fax: 81-3-3700-1425

E-mail: onodera@nihs.go.jp it is difficult to perform evaluation studies because of the short survival. On the other hand, spontaneous tumors generally only develop after more than one year in p53 (+/-) mice in which only one allele of the $\mathrm{p} 53$ gene is inactivated. A great number of validation studies of p53 (+/-) mice have been conducted, demonstrating that these animals exhibit high susceptibility to genotoxic carcinogens compared with the current mouse models ${ }^{3}$. N-butyl-N-(4-hydroxybuthyl) nitrosamine $(\mathrm{BBN})$ has been documented to induce urinary bladder carcinomas in p53 (+/-) mice earlier and with greater malignancy, the number of the p53 alleles playing an important role in bladder tumorigenesis ${ }^{4,5}$.

Currently, two different p53 knockout mice are available in Japan. One is the p53 (+/-) TSG mouse provided by Taconic Farms (Germantown, NY), derived from the C57BL6 strain with inactivation of exon 5 of one p53 allele, and the other is the p53 (+/-) CBA mouse, the F1 offspring of heterozygous p53 deficient C57BL/6J male mice with inactivation of exon 2 of one p53 allele, back-crossed with CBA females ${ }^{6}$. Administration of N-methyl-N-nitrosourea (MNU) at $30 \mathrm{ppm}$ in drinking water to p53 (+/-) TSG mice produces tumors of the glandular stomach at high incidence ${ }^{7}$, 
while at $50 \mathrm{ppm}$ in p53 (+/-) CBA mice no gastric but rather tumors of the liver and lung were the result ${ }^{8}$. In p53 (+/-) TSG mice, treatment with MNU or PB induced no liver tumors ${ }^{9}$.

Furthermore, N-nitrosodimethylamine (DMN) or Nnitrosodiethyamine (DEN) plus phenobarbital (PB) caused no liver tumors in a two stage hepatocarcinogenesis model using p53 (+/-) TSG male mice ${ }^{10,11}$, and DMN treatment of newly born p53 (+/-) mice produced liver tumors at lower incidences than in p53 $(+/+)$ mice $^{12}$. These observations indicate low susceptibility of p53 (+/-) TSG mice to chemical hepatocarcinogenesis. However, little is known regarding the susceptibility of p53 (+/-) CBA mice in this respect. Therefore, the present two stage hepatocarcinogenesis study was performed to investigate whether numbers of liver proliferative lesions are increased by treatment of female p53 (+/-) CBA mice with DMN+PB.

\section{Materials and Methods}

Thirty female p53 (+/-) CBA mice and the same number of wild-type female littermates p53 (+/+) mice were obtained from Oriental Yeast Inc. (Tokyo, Japan). Three to five mice were housed in a polycarbonated cage with white wood chips for bedding under standard conditions (room temperature, $23 \pm 2{ }^{\circ} \mathrm{C}$; relative humidity, $55 \pm 5 \%$; $12 \mathrm{hr}$ light and dark cycle) and given basal diet (CRF-1, Oriental Yeast Co., Tokyo, Japan) and tap water ad libitum. NNitrosodimethylamine (DMN) and phenobarbital (PB) were obtained from Nacalai Tesque, Inc (Kyoto, Japan) and Iwaki Seiyaku, Inc. (Tokyo, Japan), respectively. All animals were initiated with a single intraperitoneal injection of DMN (5 $\mathrm{mg} / \mathrm{kg})$; one week later, the p53 (+/-) and p53 (+/+) mice were both divided into two groups of fifteen animals each and given drinking water containing 0.05 or $0 \%$ PB for 26 weeks. Basal diet was given to all animals during the experiment period. Mice that died were subjected to a complete necropsy as soon as they were found. All surviving animals were killed under ether anesthesia at week 26. Body weights were measured once a week during the experiment period. At sacrifice, after measuring the liver weights, a wide variety of organs and tissues including the liver were fixed in $10 \%$ neutral buffered formalin, processed routinely, embedded in paraffin, sectioned at $4-5 \mu \mathrm{m}$, and stained with hematoxylin and eosin (H-E) for microscopic examination.

Immunohistochemical staining using a monoclonal antibody to proliferating cellular nuclear antigen (PCNA) (DAKO, Glostrup, Denmark) was performed at a dilution of 1: 100. Avidin-biotin peroxidase complex kits (DAKO) were applied for the performance of immunohistochemistry with 3,3'-diaminobenzidine as the chromogen and hematoxylin counterstaining. The numbers of PCNA positive cells per 100 cells in each proliferative lesion were counted from five different areas to give the PCNA labeling index (PCNA LI).

The incidences of liver proliferative lesions observed were analyzed by the Fisher's exact test. Significant differences in particular lesion types were also assessed between the p53 (+/-) and p53 (+/+) mice of DMN+PB and DMN groups. Data for the PCNA LI and multiplicity were used to generate mean and standard deviation, significant differences between groups being analyzed by the Student's $t$ test.

\section{Results}

Dead or moribund animals appeared from around weeks 3 and 7 of treatment with PB in the p53 (+/-) and p53 $(+/+)$ mice receiving $\mathrm{DMN}+\mathrm{PB}$, their final survival rates being 67 and $73 \%$ (Fig. 1). However, there was no mortality with DMN alone. Most of the animals which died had thymic lymphomas characterized by solid white to whiteyellow nodules. The body weight of p53 (+/-) and p53 (+/+) mice of the $\mathrm{DMN}+\mathrm{PB}$ group tended to decrease through the study (Fig. 2), final values being $28.6 \pm 2.0$ and $29.3 \pm 2.9 \mathrm{~g}$ in p53 (+/-) and p53 (+/+) mice of the DMN+PB group, respectively, significantly lower as compared than in the counterpart DMN alone group (32.3 \pm 4.6 and $32.7 \pm 3.8 \mathrm{~g}$ in p53 (+/-) and p53 (+/+) mice). The absolute and relative liver weights in p53 $(+/-)$ and p53 $(+/+)$ mice of the $\mathrm{DMN}+\mathrm{PB}$ group were $1.82 \pm 0.17$ and $1.88 \pm 0.17 \mathrm{~g}$, and $0.639 \pm 0.062$ and $0.644 \pm 0.066 \mathrm{~g} / 10 \mathrm{~g}$ body weight, respectively, and they were significantly increased as compared with the relevant DMN alone cases $(1.36 \pm 0.17$ and $1.31 \pm 0.13 \mathrm{~g}, 0.424 \pm 0.037$ and $0.401 \pm 0.029 \mathrm{~g} / 10 \mathrm{~g}$ body weight, respectively) in p53 (+/-) and p53 (+/+) mice. Hepatocellular proliferative lesions induced were diagnosed as altered foci, consisting of enlarged eosinophilic cells (EF), small basophilic cells (BF) or glycogen-storing clear cells (CF), and hepatocellular adenomas (Ads) (Fig. 3). The latter were solid proliferative lesions consisting of hepatocytes with slight cellular atypia, associatied with a sharp demarcation from the surrounding parenchyma and loss of the normal lobular architecture. The incidences

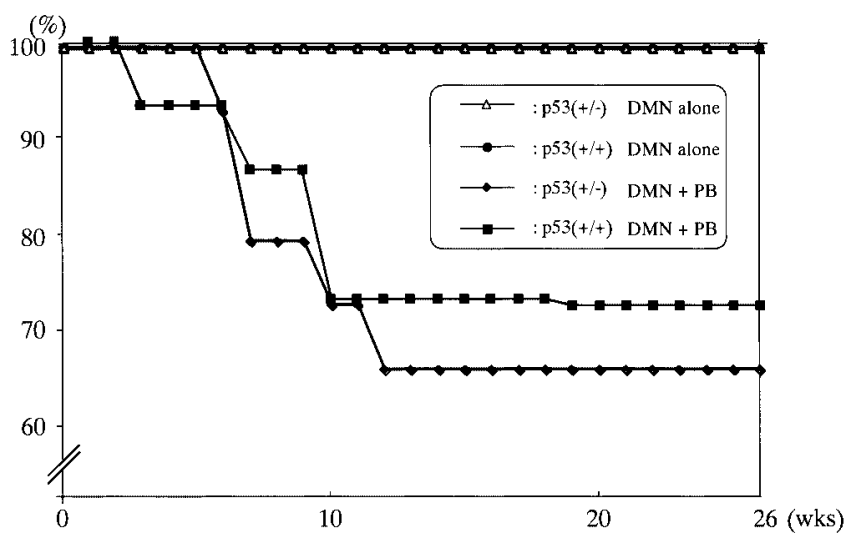

Fig. 1. Survival curves for $\mathrm{p} 53(+/-)$ or $\mathrm{p} 53(+/+)$ CBA mice treated with or without phenobarbital after dimethylnitrosamine initiation. 

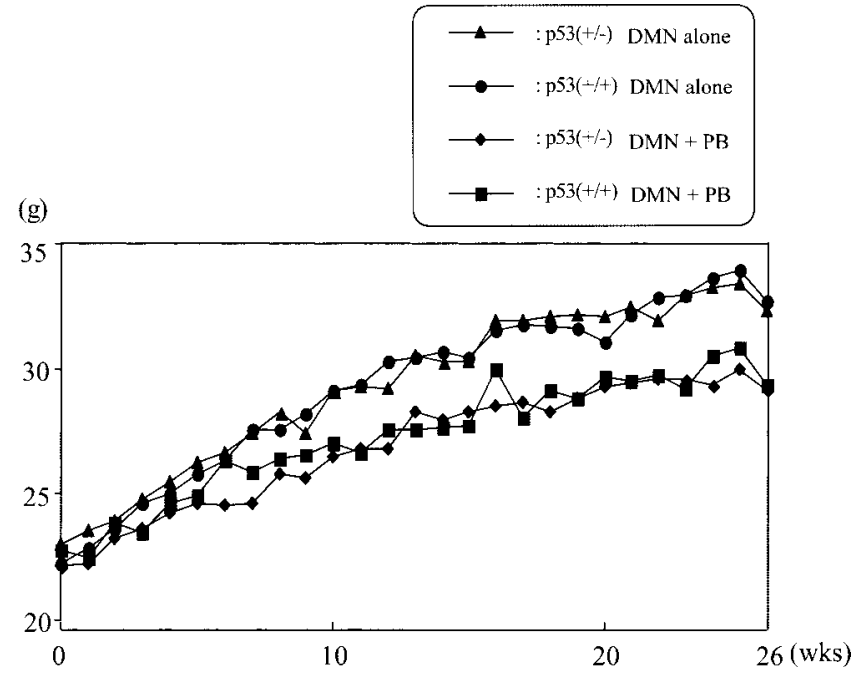

Fig. 2. Body weight curves for p53 (+/-) or p53 (+/+) CBA mice treated with or without phenobarbital after dimethylnitrosamine initiation.
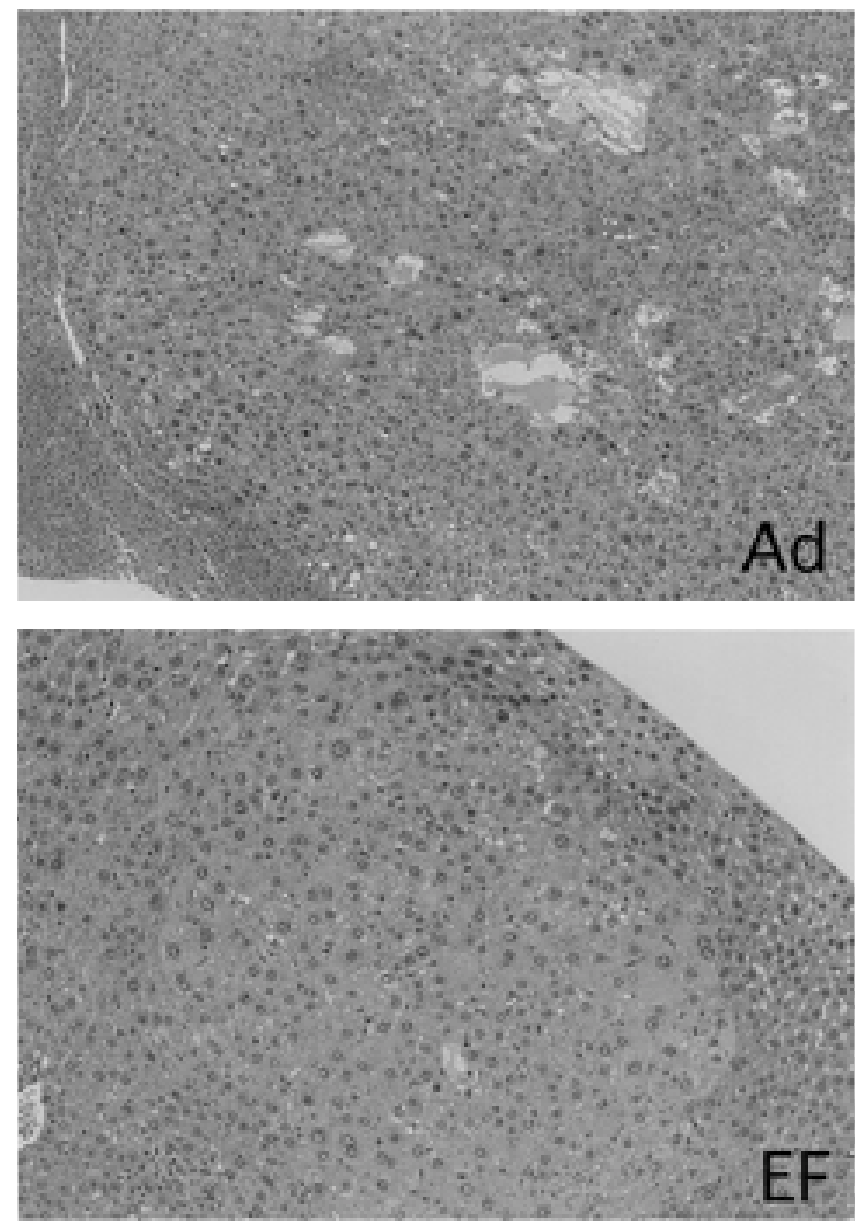

Fig. 3. Photomicrographs of a hepatocellular eosinophilic cell focus(EF), and a hepatocellular adenoma(Ad) in p53 (+/-) CBA mice treated with phenobarbital after dimethylnitrosamine initiation. (multiplicity) of EF were 90.0\% (2.1 \pm 2.4 /animal) and $54.6 \%(0.6 \pm 0.7)$ in p53 (+/-) and p53 (+/+) mice of the $\mathrm{DMN}+\mathrm{PB}$ group, respectively, with significant differences on the incidence between the two (Fig. 4, Table 1). With DMN alone EF were confined to p53 (+/-) mice, with an incidence of $6.7 \%(0.1 \pm 0.3)$. BF were seen at $6.7 \%(0.1 \pm$ $0.3)$ only in p53 (+/-) mice of the DMN alone group. CF were present only in the $\mathrm{DMN}+\mathrm{PB}$ group, at incidences (multiplicity) of $10.0 \%(0.1 \pm 0.3$ /animal $)$ and $9.1 \%(0.2 \pm$ $0.5)$ in p53 (+/-) and p53 (+/+) mice, respectively. Ads were seen in the $\mathrm{DMN}+\mathrm{PB}$ group, with incidences (multiplicity) of $60.0 \%(2.7 \pm 4.5)$ and $27.3 \%(0.2 \pm 0.4)$ in p53 (+/-) and p53 $(+/+)$ mice, respectively, the differences being significant.

The PCNA LI for EF and Ads in p53 (+/-) mice of the $\mathrm{DMN}+\mathrm{PB}$ group were significantly higher than in their counterparts in p53 (+/+) mice (Fig. 5).

\section{Discussion}

It has been reported that carcinogenesis and malignancy of proliferative lesions in humans is intimately linked to loss, mutation or instability of the p53 gene which plays a key role in control of the cell cycle and apoptosis ${ }^{1,13}$. Recently, new testing approaches with newborn, two stage carcinogenesis and genetically altered animal models have been proposed at the International Conference on Harmonization ( $\mathrm{ICH})$ as alternatives to the current mouse carcinogenicity studies. With rapid progress in gene technology, specifically altered animals have attracted great attention with introduction of human oncogenes or inactivated suppressor oncogenes. At the present moment, the most widely available transgenic mice (Tg-mice) in Japan are rasH2, Tg/AC, and p53 (+/-) strains. Among these, p53 (+/-) mice have been validated extensively by the U.S. National Institute of Environmental Health Sciences, so that basic data have accumulated and further application to carcinogen research is to be expected. Responding to the validation studies in the USA, we are now also performing studies on p53 (+/-) CBA mice ${ }^{14}$. The life span spontaneous incidences of hepatocellular tumors in CBA mice are reported to be low ${ }^{15}$ and historically p53 (+/-) CBA mice reared in our laboratory demonstrated extremely few lesions at 6 months of age. In the present study, hepatocellular adenomas occurred not only at an incidence of $60 \%$ in p53 $(+/-)$ mice, but eosinophilic foci considered as precursors were induced at the incidences of 90 and $54.6 \%$ in p53 (+/-) and p53 (+/+) mice, respectively. These data suggest high sensitivity to development of hepatocellular proliferative lesions with PB treatment after DMN initiation in CBA mice. DMN is known to induce mutations of hepatocytes ${ }^{3,16}$ and hepatocellular tumors ${ }^{17}$. Another hepatocarcinogen, flumequine, has been previously reported to induce hepatocellular foci/tumors in p53 (+/-) CBA mice ${ }^{20}$, whereas other ones, diethylnitrosamine and MeIQx, do not affect hepatocarcinogenesis in p53 (+/-) TSG mice ${ }^{11,21}$. Treatment of $\mathrm{PB}$ alone has also been described to induce liver tumors in 
DMN alone
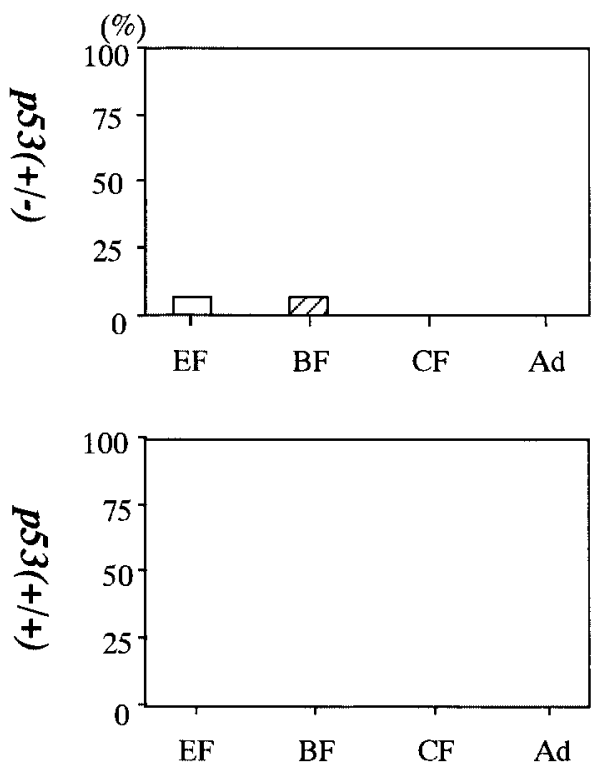

$D M N+P B$
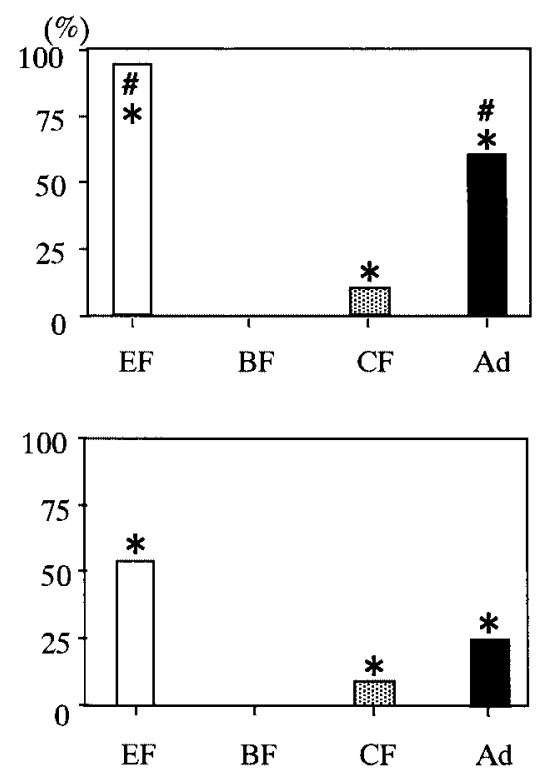

* : Significantly different from $\mathrm{p} 53(+/+)$ DMN alone at $\mathrm{p}<0.05$

\# : Significantly different from $\mathrm{p} 53(+/+) \mathrm{DMN}+\mathrm{PB}$ at $\mathrm{p}<0.05$

EF:eosinophilic foci BF:basophilic foci CF:clear cell foci Ad :hepatocellular adenoma

Fig. 4. Incidences of liver proliferative lesions in p53 (+/-) or p53 (+/+) CBA mice treated with or without phenobarbital after dimethylnitrosamine initiation.

Table 1. Multiplicity of Liver Proliferative Lesions in p53 (+/-) or p53 (+/+) CBA Mice Treated with or without Phenobarbital after Initiation of Dimethylnitrosamine

\begin{tabular}{|c|c|c|c|}
\hline & & p53 (+/-) & p53 (+/+) \\
\hline \multirow[t]{2}{*}{ Eosinophilic foci (EF) } & DMN alone & $0.07 \pm 0.26^{\mathrm{a}}$ & $0^{\mathrm{a}}$ \\
\hline & $\mathrm{DMN}+\mathrm{PB}$ & $2.10 \pm 2.42^{b}$ & $0.64 \pm 0.67^{\mathrm{c}}$ \\
\hline$-----\cdots$ & --- & ---- & $--\ldots$ \\
\hline \multirow[t]{2}{*}{ Basophilic foci (BF) } & DMN alone & $0.07 \pm 0.26$ & 0 \\
\hline & $\mathrm{DMN}+\mathrm{PB}$ & 0 & 0 \\
\hline$------\cdots$ & --- & $---\ldots$ & --- \\
\hline \multirow{2}{*}{ Clear cell foci (CF) } & DMN alone & 0 & 0 \\
\hline & $\mathrm{DMN}+\mathrm{PB}$ & $0.10 \pm 0.32$ & $0.15 \pm 0.52$ \\
\hline$------\ldots$ & --- & ---- & --- \\
\hline \multirow[t]{2}{*}{ Hepatocellular adenoma (Ad) } & DMN alone & 0 & 0 \\
\hline & $\mathrm{DMN}+\mathrm{PB}$ & $2.70 \pm 4.52$ & $0.15 \pm 0.38$ \\
\hline
\end{tabular}

a: $n=15, b: n=10, c: n=11$

YellowAvy/A mice ${ }^{18}$, but at 500 or 1000 ppm for 26 weeks produced only hypertrophy of hepatocytes p53 (+/-) TSG mice ${ }^{9}$. Moreover, no liver tumors were noted in a two stage hepatocarcinogenesis experiment using DMN and PB in the same animals ${ }^{10}$. These data thus suggest low susceptibility of p53 (+/-) TSG mice and relatively high susceptibility of p53 (+/-) CBA mice to hepatocarcinogenesis, though the reasons remain unclear.
Cell proliferative activity in targeting organs was not found to be necessarily high when a variety of carcinogens were administered to p53 (+/-) mice, but chemicals targeting the urinary bladder or skin caused high cell proliferation ${ }^{5,19}$. In the present study, the PCNA indices for eosinophilic cell foci and hepatocellular adenomas were higher in p53 (+/-) than in p53 $(+/+)$ CBA mice. Thus the results of the present study indicate that p53 (+/-) CBA mice have high 
$30(\%)$

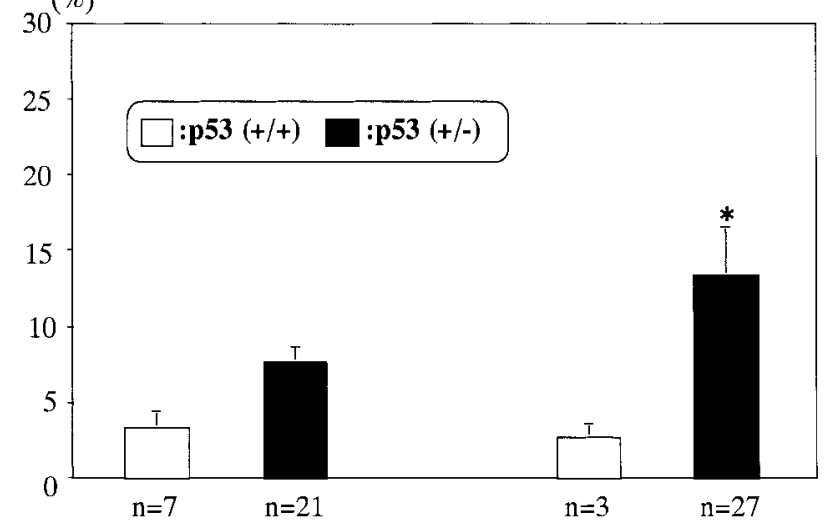

\section{Eosinophilic foci Hepatocellular adenoma \\ * : Significantly different from $\mathrm{p} 53(+/+)$ at $\mathrm{p}<0.05$}

Fig. 5. Frequencies of PCNA positive cells in eosinophilic foci and hepatocellular adenomas in p53 (+/-) or p53 (+/+) CBA mice treated with phenobarbital after dimethylnitrosamine initiation.

susceptibility to liver tumor induction under DMN-initiated condition and consequently utility for evaluating hepatocarcinogenic potential. Differences in sensitivity between p53 (+/-) knockout strains is thought to depend on where and how the p53 gene was altered genetically, and the strains of animals used for backcross. Further studies are needed to evaluate the tumorigenicity in p53 (+/-) CBA mice of other carcinogens which induce tumors in other organs, i.e the urinary bladder in p53 (+/-) TSG mice ${ }^{4,5}$. When p53 (+/-) mice are scheduled for use in evaluation of the carcinogenic potential of newly developed chemicals, strain differences in p53 (+/-) mice sensititvity should be taken into account.

Acknowledgements: This work was supported in part by Special Coordination Funds for Promoting Science and Technology of the Science and Technology Agency of Japan and a grant-in-aid from the Ministry of Health and Welfare of Japan.

\section{References}

1. Hollstein M, Sidransky D, Vogelstein B, and Harris CC. P53 mutations in human cancers. Science 1991; 253: 49-53.

2. Tennant RW, Spalding J, and French JE. Evaluation of transgenic mouse bioassays for identifying carcinogens and noncarcinogens. Mutation Res 1996; 365: 119-127.

3. Harvey M, McArthur MJ, Montgomery CA Jr., Butel JS, Bradley A, and Donehower LA. Spontaneous and carcinogen -induced tumorigenesis in p53- deficient mice. Nat Genet 1993; 5: 225-229.

4. Ozaki K, Sukata T, Yamamoto S, Uwagawa S, Seki T, Kawasaki H, Yoshitake A, Wanibuchi H, Koide A, Mori Y, and Fukushima S. High susceptibility of p53 (+/-) knockout mice to N-butyl-N-(4-hydroxybutyl)nitrosamine urinary bladder carcinogenesis and lack of frequent mutation in residual allele. Cancer Res 1998; 58: 3806-3811.

5. Yamamoto S, Min W, Lee CCR, Salim EI, Wanibuchi H, Sukata T, and Fukushima S. Enhacement of urinary bladder carcinogenesis in nullizygous p53-deficient mice by Nbutyl-N-(4-hydroxybutyl)nitrosamine. Cancer Letters 1999; 135: $137-144$

6. Tsukada T, Tomooka Y, Takai S, Ueda Y, Nishikawa S, Yagi T, Tokunaga T, Takeda N, Suda Y, Abe S, Matsuo I, Ikawa Y, and Aizawa S. Enhanced proliferative potential in culture of cells from p53-deficient mice. Oncogene 1993; 8: 3312-3322.

7. Ohgaki H, Fukuda M, Tohma Y, Huang H, Stoica G, Tatematsu M, and LA Donehower. Effect of intragastric application of $\mathrm{N}$-methylnitrosourea in p53 knockout mice. Mol Carcinogenesis 2000; 28: 97-101.

8. Takagi H, Mitsumori $\mathrm{K}$, Nishikawa A, Onodera $\mathrm{H}$, Furukawa F, Kasahara K, and Hirose M. Lack of carcinogenic sensitivity of the glandular stomach in heterozygous p53 knockout mice given N-methyl-Nnitrosourea in their drinking water for 26 weeks. Asian Pacific J Cancer Prevent 2000; 1: 1-10.

9. Johe ES, Sandra WC, Roderick TB, Julio CD, Dale LM, and Carl LA. Phenobarbital does not promote hepatic tumorigenesis in a twenty-six-week bioassay in p53 heterozygous mice. Toxicol Pathol 1998; 26: 492-500.

10. Sukata T, Morimura K, Tokuyama Y, Ozaki K, Uwagawa S, Wanibuchi H, Seki T, Yoshitake A, Tsuda H, and Fukushima S. Susceptibility to hepatocarcinogenesis of p53 knockout mice. Proceeding of 55th Annual Meeting of Jap. Cancer Association pp.265, 1996.

11. Kemp CJ. Hepatocarcinogenesis in p53-deficient mice. Mol Carcinogenesis 1995; 12: 132-136.

12. Balachandra Dass S, Thomas JB, Robert HH, and Daniel AC. Evaluation of the trasgenic p53+/- mouse for detecting genotoxic liver carcinogens in a short-term bioassay. Cancer Lett 1999; 143: 81-85.

13. Shi ST, Yang GY, Wang L, Xue Z, Feng B, Ding W, Xing $\mathrm{EP}$, and Yang CS. Role of $\mathrm{p} 53$ gene mutations in human esophageal carcinogenesis: Results from immunohistochemical and mutation analyses of carcinomas and nearby non-cancerous lesions. Carcinogenesis 1999; 20: 591-597.

14. Mitsumori K, Onodera H, Shimo T, Yasuhara K, Takagi H, Koujitani T, Hirose M, Maruyama C, and Wakana S. Rapid induction of uterine tumors with $\mathrm{p} 53$ point mutations in heterozygous p53 deficient CBA mice given a single intraoeritoneal administration of $\mathrm{N}$-ethyl-N-nitrosourea. Carcinogenesis 2000; 21: 1039-1042.

15. Smith GS, Walford RL, and Mickey RM. Lifespan and incidence of cancer and other diseases in selected long-lived inbred mice and their F1 hybrids. J Natl Cancer Inst 1973; 50: $1195-1213$.

16. Armato U, Wu J, Menegazzi M, Menapace L, Ribecco M, Testolin L, Carcereri De Prati A, and Suzuki H. The in utero initiation with DMN alters the complement of cytosolic glutathione S-transferases and the phenobarbital-induced expression of c-jun and c-myc oncogenes in primary neonatal rat hepatocytes. Cytotechnology 1993; 11 (Suppl 1): $\mathrm{S} 18-20$.

17. Anderson LM, Logsdon D, Ruski S, Fox SD, Issaq HJ, Kovatch RM, and Riggs CM. Promotion by polychlorinated biphenyls of lung and liver tumors in mice. Carcinogenesis 
1994; 15: 2245-2248.

18. Wolff GL, Morrissey RL, and Chen JJ. Susceptible and resistant subgroups in genetically identical populations: Response of mouse liver neoplasia and body weight to phenobarbital. Carcinogenesis 1986; 7: 1935-1937.

19. Sukata T, Ozaki K, Uwagawa S, Seki T, Wanibuchi H, Yamamoto S, Okuno Y, and Fukushima S. Organ-specific, carcinogen-induced increases in cell proliferation in $\mathrm{p} 53-$ deficient mice. Cancer Res 2000; 60: 74-79.

20. Takizawa T, Mitsumori K, Takagi H, Onodera H, Yasuhara
K, Tamura T, and Hirose M. Modifying effects of flumequine on dimethylnitrosamine-induced hepatocarcinogenesis in heterozygous p53 dificient CBA mice. J Toxicol Pathol 2001; 14: 135-143.

21. Cheol Beom Park, Dae Joong Kim, Uehara N, Takasuka N, Baba-Toriyama $\mathrm{H}$, and Tsuda $\mathrm{H}$. Heterozygous p53deficient mice are not susceptible to 2-amino-3,8dimethylimidazo[4,5-f]quinoxaline(MeIQx) carcinogenicity. Cancer Lett 1999; 139: 177-182. 